\title{
CONCEPÇÕES DAS FORMAS ESTATAIS ATRELADAS AS SOCIEDADES: A FRAGILIDADE DO ESTADO DEMOCRATICO DE DIREITO DIANTE O POVO ÍCONE
}

\section{CONCEPTIONS OF FORMS STATE LINKED SOCIETIES: FRAGILITY DEMOCRATIC RULE OF LAW FORWARD ICON PEOPLE}

\author{
${ }^{1}$ Clarice Souza Prados
}

\begin{abstract}
Resumo
O presente artigo objetiva analisar quem é o povo no Estado Democrático de Direito. Inicia-se abordando a sociedade moderna desde a formação do Estado Absolutista até o Estado Democrático, demonstrando que do absolutismo até a democracia a sociedade que o Estado atende é composta por uma classe privilegiada e não ao povo, caracterizando em uma democracia representada por uma classe, configurando esvaziamento do sistema democrático. Para tanto, considera as definições de povo, chegando à conclusão que o povo que o Estado Democrático de Direito representa é povo ícone, fragilizando a concretude da democracia, consequentemente a efetividade dos direitos humanos.
\end{abstract}

\section{Palavras-chave:}

Estado; Povo; Democracia; Estado Democrático de Direito.

\begin{abstract}
:
This article aims to analyze who is that people in the democratic rule of law. Begins addressing modern society since the formation of the Absolutist State to the Democratic State, showing that the absolutism to democracy society that the State meets consists of a privileged class, not the people, featuring in a democracy represented by a ruling class, that sets up the emptying of the democratic system. Therefore, consider the people of settings, reaching the conclusion that the people that the democratic rule of law is the people's icon handicapping the concreteness of democracy, hence the effectiveness human rights.
\end{abstract}

\section{Keywords:}

State; people; democracy; democratic rule of law.

\footnotetext{
${ }^{1}$ Mestranda em Direitos Fundamentais pela Universidade de Itaúna - MG,(Brasil).Pós-graduada em Direito Ambiental pela Universidade Gama Filho e graduada pela Universidade de Itaúna - MG,(Brasil).E-mail: claprados@yahoo.com.br
} 


\section{INTRODUÇÃO}

O presente artigo inicia abordando a sociedade moderna no Estado Absolutista, demonstrando uma sociedade estamental. Já no século XVIII surgia uma nova classe, a burguesia, que conseguiu seus objetivos através de uma Revolução (denominada de Revolução Francesa), em que lutou para que o Estado atendesse seus interesses, não intervindo, sendo um Estado Liberal.

Na sequência, o proletariado, não satisfeito por ser excluído das finalidades estatais, batalhou para que o Estado também atendesse aos seus interesses, momento em que o Estado deixa de ser um Estado Liberal e passa a ser um Estado Social.

A sociedade em constante transformação exige uma mudança da forma estatal para que o Estado possa anteder as necessidades que vão surgindo com essas transformações. Assim sendo, diante de uma sociedade com multiplicidades de atores, o Estado Social passa para um Estado Democrático de Direito, que em nome do povo e para povo governa.

Portanto, a indagação que surge e que este presente artigo objetiva responder é quem é o povo que o Estado Democrático de Direito representa. Para tanto, fez-se imprescindível analisar as definições feitas por Friedrich Müller (2010) em sua obra "Quem é o Povo? A questão fundamental da democracia”.

Tem-se, então, que o objetivo desse artigo é responder quem é o povo que o Estado Democrático de Direito representa e, consequentemente, se essa representação consolida ou enfraquece a democracia.

Müller conceitua o povo partindo de quatro vieses: "povo" como povo ativo; "povo" como instância global de atribuição de legitimidade; "povo" como ícone; "povo" como destinatário das prestações civilizatórias do Estado.

A partir desses conceitos apresentados pelo citado autor o presente artigo responde quem é o povo que o Estado Democrático de Direito representa, e mais, quem é o povo que a Constituição da República Federativa do Brasil de 1988 visa elucidar quando prescreve que “todo poder emana do povo".

Por fim, o presente artigo analisa se esse povo que de fato é representando por essa última modalidade estatal enfraquece ou fortalece o sistema democrático. Não se olvidando que a democracia e os direitos humanos estão entrelaçados, conforme demonstrará de forma bem sucinta. 
Para feitura do presente trabalho e para elucidar as conclusões de forma mais precisa e claras possíveis foi utilizado o método de pesquisa dedutivo, através do estudo bibliográfico.

\section{A SOCIEDADE MODERNA: DO ABSOLUTIMO AO ESTADO DEMOCRÁTICO DE DIREITO}

\subsection{O DECLINIO DO ESTADO ABSOLUTISTA E A FORMAÇÃO DA SOCIEDADE MORDERNA}

Com a formação dos Estados, no século XVI, há um rompimento com feudalismo, nascendo uma nova instituição, diferente do que até então já se tinha constatado. As formas de Estados foram recebendo adjetivos, inicia-se com o Estado Absolutista, em que os poderes se concentram na mão de uma só pessoa: o rei. Esse modelo de Estado se caracterizou pela formação da sociedade estamental, em que no ápice da pirâmide social encontra-se o rei, logo abaixo o clero e depois a nobreza, por fim, na base da pirâmide e constituindo a maior parte da população tem-se o povo, formado por um grupo heterogêneo que não participavam das decisões políticas e sobre eles recaíam todos os impostos.

Durante esse período histórico surge uma nova classe na sociedade dita moderna: a burguesia, que era incluída na base da pirâmide, formando o povo. Não satisfeita por ser excluída das decisões políticas do Estado e compelida a arcar com os impostos, sustentando o reino, o clero e os nobres, e ademais, ficando excluída dos privilégios, eclode a Revolução Francesa de 1789 que afasta o Estado Absolutista, ou seja, separa a primeira fase do Estado com a segunda fase, sobrevém, portanto, de um Estado intervencionista para um Estado Liberal. Nesse momento não há em que se falar em uma ruptura da instituição estatal, mas apenas em uma mudança.

A Revolução Francesa, conhecida também como Revolução Burguesa, objetivava limitar o poder dos reis, submetendo-os a vontade da lei, e esta era uma resultante da vontade do povo, bem como visava à abstenção do Estado de intervir, nomeando essa nova roupagem da forma estatal de Estado Liberal, momento em que nasce a concepção de direitos fundamentais do homem e a participação popular do povo no governo, ainda que de forma bastante limitada.

Foi assim - da oposição histórica e secular, na Idade Moderna, entre a liberdade do indivíduo e o absolutismo do monarca - que nasceu a primeira noção do Estado de Direito, mediante um ciclo de evolução teórica e decantação conceitual, que se 
completa com a filosofia política de Kant. Esse primeiro Estado de Direito, com seu formalismo supremo, que despira o Estado de substantividade ou conteúdo, sem força criadora, reflete a pugna da liberdade contra o despotismo na área continental européia." (BONAVIDES, 2001, p.41)

Esse primeiro Estado de Direito, o Estado Liberal, consistia na limitação do poder do rei em benefício do direito de liberdade do individuo, entende-se, a liberdade da burguesia, a nova classe que emergia nessa época, composta de poder econômico, mas não de poder político. Há a construção de algo novo, a burguesia inaugura o Estado Constitucional, uma vez que essa nova classe social precisa de garantias e de liberdades econômicas. O dever do estado deixa de ser intervencionista e passa ser o estado para assegurar garantias, chama-se Estado Mínimo.

Verifica-se, portanto, que a premissa capital do Estado Moderno é a conversão do Estado absoluto em Estado Constitucional; o poder já não é de pessoas, mas de leis. São as leis, e não as personalidades, que governam o ordenamento social e político. A legalidade é a máxima de valor supremo e se traduz com toda energia no texto dos Códigos e das Constituições. (BONAVIDES, 2012, p. 43)

Entretanto, essa forma de Estado Moderno beneficiou uma parcela do povo, a burguesia, mas para o restante da população nada se modificou. Nesse contexto, nota-se, como explica Canotilho (1999), que o bem do povo e os interesses do Estado foram (e ainda são) invocados a torto e a direito a fim de dar cobertura a privilégios das classes dominantes, insinuando-se a escandalosa identificação dos interesses dessas classes como os interesses e o bem comum de todos os cidadãos.

\subsection{O PROLETÁRIO E A NECESSIDADE DE UM NOVO ESTADO: DO ESTADO LIBERAL AO ESTADO SOCIAL}

Com revolução industrial nasce uma nova categoria social: o proletariado. Esse não participa das decisões político, bem como não possuía garantias e muito menos privilégios, sendo assim inicia-se uma disputa política, tal como fez a burguesia com a monarquia na Revolução Francesa.

Essa nova categoria social, que emergiu com o crescimento industrial e que ganhou contornos definitivos com a Segunda Guerra Mundial, visava disputar novos direitos que são os direitos sociais. Esses novos direitos passam a compor o rol dos direitos humanos.

Nesse contexto histórico, vê-se o Estado Mínimo se transformando em Estado do Bem-Estar Social. Não há rompimento, mas apenas uma mudança da forma estatal, em que o Estado Social continua sendo um Estado Liberal, já que mantém a característica do liberalismo. Portanto, essa nova mutação do Estado é alicerçada em uma economia capitalista 
que é excludente, mas com o acréscimo de prestações estatais que buscam a redução das desigualdades.

No Estado liberal bastava o reconhecimento dos direitos, como o direito de liberdade, entretanto com o Estado Social há a necessidade de implementar os direitos que o próprio Estado reconhece. Assim sendo, há uma política de inclusão, reduzindo as desigualdades pela atuação do estado, através de atividades prestacionais por parte do Estado a fim de atender as necessidades de uma nova classe social que emerge nesse contexto: o proletariado. Entretanto, ainda permanece uma economia de exclusão, devido ao sistema capitalista.

Nesse diapasão, o Estado do Bem-Estar Social surge devido à emergência de novos atores na sociedade moderna que exigem do Estado mais que uma política liberal, uma política prestacional necessária para atender os anseios dessa nova classe social. José Luis Bolzan de Morais assim explica:

\begin{abstract}
A democratização das relações sociais, paulatinamente conquistadas - mesmo ante todos os retrocessos experimentados no curto Século XX, com todas os seus desvios autoritários e totalitários -, significou, por outro lado, a abertura de canais que permitiram a quantificação e a qualificação das demandas por parte da sociedade civil em face, em especial, da incorporação de novos autores - movimentos sociais, particularmente os movimentos dos trabalhadores ingressos no novo sistema fabril , bem como diante das questões novas trazidas pelos mesmos e que implicavam não apenas na necessidade de respostas inéditas por seu conteúdo, como também precursoras em razão dos mecanismos que se teve que lançar mão para dar conta com suficiência e eficiência das mesmas, tais foram as novas políticas sociais vinculadas aos direitos sociais de caráter prestacional, e.g. regulação das relações de trabalho, seguridade social, educação, saúde, infraestrutura urbana, política energética, política de transportes, infraestrutura industrial, câmbio, juros, etc. (MORAIS, 2011, p. 38).
\end{abstract}

Percebe-se que a forma estatal se transmuda de acordo com o surgimento da necessidade dos novos atores no contexto histórico, primeiramente a burguesa que aspira por um estado abstencionista, não intervencionista, de prestações negativas, constituindo-se o Estado Liberal. Logo mais, emerge a classe dos proletariados que objetiva por prestações positiva do estado, transformando em um Estado Social.

\title{
2.3 DO ESTADO SOCIAL AO ESTADO DEMOCRÁTICO DE DIREITO
}

Ocorre que, posteriormente, a sociedade, em constante transformação como é da natureza humana, se torna uma sociedade até então não existente, uma sociedade complexa, em que há uma multiplicidade de atores e cada qual com suas necessidades. Esses novos 
atores em busca de uma vida digna começam a participar (ou pelos menos tentam) das decisões políticas, momento em que o Estado Social se transforma em um Estado Democrático de Direito.

Não há uma revolução com essa nova forma estatal, como também não há uma ruptura com o Estado Liberal, bem como com o Estado Social, o que ocorre é uma transformação, já que o Estado Democrático de Direito em sua essência tem caráter transformador da realidade, indo mais além das outras duas formas estatais.

O Estado Democrático de Direito tem um conteúdo transformador da realidade, não se restringido, como o Estado Social de Direito, a uma adaptação melhorada das condições sociais de existência. Assim, o seu conteúdo ultrapassa os aspecto material de concretização de uma vida digna ao homem e passa a agir simbolicamente como fomentador da participação pública no processo de construção e reconstrução de um projeto de sociedade, apropriando-se do caráter incerto da democracia para veicular uma perspectiva de futuro voltada a produção de uma nova sociedade, onde a questão da democracia contém e implica, necessariamente, a solução do problema das condições materiais de existência. (STRECK; MORAIS, 2010, p. 97, 98)

Em apertada síntese, observa-se que a finalidade do Estado Absolutista é servir totalmente as vontades dos reis. Com o surgimento do Estado Liberal o individuo passa a ser o centro, o Estado deve deixar de fazer algo em prol do direito de liberdade do individuo. Já no Estado Social as preocupações se voltam a um grupo, visando prestações positivas para atender as necessidades desse grupo.

Por fim, emerge uma sociedade complexa que objetiva maior participação pública, que aspira por um governo voltado a atender as necessidades da população, eclodindo o Estado Democrático de Direito.

A primeira é o Estado constitucional da separação dos Poderes (Estado Liberal), a segunda, o Estado constitucional dos direitos fundamentais (Estado Social) a terceira, o Estado constitucional da Democracia participativa (Estado DemocráticoParticipativo).

Não há propriamente ruptura no tempo tocante ao teor dessas três formas impetrantes de organização estatal, senão a metamorfose, que é o aperfeiçoamento e enriquecimento e acréscimo, ilustrados pela expansão crescente dos direitos fundamentais bem como pela criação de novos direitos. (BONAVIDES, 2012, p. 43)

Na concepção de Lênio Luiz Streck e José Luiz Bolzan de Morais (2010) o Estado Democrático de Direito tem um conteúdo transformador da realidade, tem como objetivo a igualdade. O seu conteúdo ultrapassa os aspecto material de concretização de uma vida digna ao homem e passa a agir objetivando a participação pública no processo de construção e reconstrução de uma sociedade, buscando a produção de uma nova sociedade em que a questão da democracia contém e implica a solução do problema das condições materiais de existência. A lei passa a ser um instrumento de transformação da sociedade. 
Por conseguinte, o Estado Democrático de Direito ultrapassa a formulação do Estado Liberal de Direito, bem como suplanta o Estado Social de Direito, visando a concretizar a transformação da realidade: “o Estado Democrático é plus normativo em relação às formulações anteriores". (STRECK; MORAIS, 2010, p.99)

Nessa conjuntura, surge juntamente com a democracia a prevalência dos direitos humanos, uma vez que para consolidar um Estado Democrático de Direito é imprescindível consagrar a eficácia e a efetividade dos direitos humanos, pois há uma intensa conexão entre a democracia e os direitos humanos.

\begin{abstract}
Para a consolidação da Democracia, emerge o desafio da construção de um novo paradigma, pautado por uma agenda de inclusão, que seja capaz de assegurar um desenvolvimento sustentável, mais igualitário e democrático, nos planos local, regional e global. A prevalência dos direitos humanos e do valor democrático há de constituir a tônica deste novo paradigma, sob as perspectivas de gênero, raça e etnia. (PIOVESAN, s/d, p. 5)
\end{abstract}

No Brasil a democracia nasce com o fim dos governos da ditadura militar. O documento que rompe com essa ditadura, instituindo o Estado Democrático de Direito, é a Constituição da República Federativa do Brasil de 1988 (CR/88), que em seu preâmbulo declara: "Nós, representantes do povo brasileiro, reunidos em Assembleia Nacional Constituinte para instituir um Estado Democrático...” e em seu $\S 1^{\circ}$ do primeiro artigo prescreve que “todo poder emana do povo”. Assim sendo, tem-se que o Estado Democrático de Direito emergiu para atender as necessidades e as vontades do povo.

\title{
2. O POVO: A ESSENCIA DO ESTADO DEMOCRÁTICO DE DIREITO
}

\subsection{POVO: UMA TENTATIVA DE DEFINÍ-LO}

A essência fundamental do Estado Democrático de Direito é o povo, é um Estado do povo e para o mesmo. Tanto que a $\mathrm{CR} / 88$ objetiva atender às necessidades do povo. Mas o questionamento que se faz é: quem é povo?

Definir quem é o povo não é uma tarefa singela, uma vez que é composto por diversos conceitos, definições e finalidades. Friedrich Müller (2010) em sua obra "Quem é o Povo? A questão fundamental da democracia" analisa o conceito de povo partindo de quatro vieses: "povo" como povo ativo; "povo" como instância global de atribuição de legitimidade; "povo" como ícone; "povo" como destinatário das prestações civilizatórias do Estado. 
Para Müller o povo ativo se constitui nos titulares de nacionalidade de acordo com as determinações normativas do texto constitucional, o que se considera para definir povo, sob esse viés, é a totalidade dos eleitores.

É muito singelo, em uma democracia, considerar o povo como a totalidade dos eleitores, é confundir o conceito de povo com o de cidadão. Ademais, é atribuir ao povo ativo uma responsabilidade muito elevada perante um sistema tão complexo como o sistema democrático. Nas palavras de Müller (2010, p. 47) “O povo ativo não pode sustentar sozinho um sistema tão repleto de pressupostos”.

O sistema eleitoral é fundamentado em uma deliberação em que compete a maioria decidir. Sendo assim, parte do povo não estaria sendo representada, uma vez que a minoria vencida não será representada por quem ela delegou. Partindo dessa premissa surge uma questão emblemática: se a democracia é o governo do povo e para o povo como justificar a exclusão desse povo minoritário?

Considerando esse sistema de eleição baseado na vontade da maioria (sistema majoritário) tem-se o que Pierre Rosanvallon define como legitimidade incomplenta:

En efecto, la consumación satisfactoria de um procedimento de seleccion se acompanha entonces de uma legitimación incumplida. La distancia entre estos dos elementos es limitada em el caso de la elección de uma asamblea representativa, ya que la cantidad y la diversidade de interesses y opiniones, a falta de uma verdadeira voluntad general (que, además, nunca preexiste a la expresión ciudadana). (2015, p. 149)

Acresce a isso, na concepção de Norbeto Bobbio (2000), que o problema da regra da maioria se pauta evidentemente no que se refere às minorias étnicas que sempre sucumbem no caso de se adotar rigidamente o princípio da maioria. Mesmo diante dessa problemática em que exclui um grupo minoritário Bobbio afirma que: "apesar de tudo, a regra da maioria resiste a todas as críticas porque ainda não se descobriu nada melhor". (BOBBIO, 2000, p. 447)

Na sequência Müller analisa o "povo" como instância global de atribuição de legitimidade. Nesse aspecto o povo não é apenas uma fonte ativa da instituição de normas através das eleições, vai um pouco além, pois o povo elege seus representantes, que são os responsáveis pela elaboração de normas, que vinculam as ações e interesses do próprio povo e para o mesmo. Nesse contexto, o povo é o destinatário das prescrições, em conexão com os deveres, direitos e funções de proteção.

O referido autor afirma que somente há a instância global de atribuição de legitimidade onde há ao mesmo tempo a figura do povo ativo. Completa que apenas pode falar em povo ativo quando são praticados e respeitados os direitos fundamentais individuais, 
como também os direitos fundamentais políticos, uma vez que esses direitos fundamentam juridicamente uma sociedade libertária, um estado democrático:

Sem a prática dos direitos do homem e do cidadão, "o povo" permanece uma metáfora ideologicamente abstrata de má qualidade. Por meio da prática dos human rights ele se torna, em função normativa, "povo de um país" [Staatsvolk] de uma democracia capaz de justificação - e torna-se ao mesmo tempo "povo" enquanto instância de atribuição global de legitimidade, povo legitimante. (MÜLLER, 2010. p. 52)

O terceiro viés de conceito de povo de Müller é o povo como "ícone" que se constitui na concepção de um povo hipotético, abandona o povo e "desrealiza" a população. Não se refere a nenhum cidadão ou grupo de pessoas, uma vez que importa "criar o povo, ou seja, esse não existe na vida real. Acrescenta que a necessidade dessa criação, do povo ícone, objetiva atender a vontade das minorias detentoras dos poderes, que em nome de seus interesses discursam que agem em nome e para o povo.

Em termos bem genéricos, a iconização reside por igual também [nicht zuletzt] no empenho de unificar em "povo" a população diferenciada, quando não cindida pela diferença segundo o gênero, as classes ou camadas sociais, frequentemente também segundo a etnia e a língua, a cultura e a religião. No uso ideológico, tudo isso tornaria a função legitimadora precária.

[...] A população heterogênea é "uni" ficada em benefício dos privilegiados e dos ocupantes do establishtment, é ungida como "povo" e fingida - por meio do monopólio da linguagem e da definição nas mãos do(s) grupo(s) dominante(s) como constituinte e mantenedora da constituição. Isso impede, conforme se deseja, de dar um nome às cisões sociais reais, de vive-las [austragen] e consequentemente trabalha-las. A simples fórmula do "poder constituinte do povo" já espelha ilusoriamente o uno. (MÜLLER, 2010, p. 59)

Por fim, Müller analisa o povo como destinatário das prestações civilizatórias do Estado, sendo aquele que, ao lado do povo enquanto instância de atribuição, deve abarcar também a minoria dos cidadãos ativos, não importa quão mediata ou imediatamente, de competências de decisão e de sancionamento claramente definidas; em segundo lugar a legitimidade ocorre pelo modo mediante o qual todos, o povo inteiro, a população, a totalidade dos atingidos são tratados por tais decisões e seu modo de implementação. Os dois aspectos são resultados de uma cultura jurídica desenvolvida por parte do Estado, das circunstâncias de fato de inibição da ação estatal, bem como de prestações estatais diante das pessoas atingidas.

Assim sendo, nesse aspecto, o povo destinatário de prestações civilizatórias do Estado são as pessoas que se encontrarem no território de um Estado e ali fixam residência, trabalham, estabelecem laços pessoais e materiais. 
Feito a analise política-jurídica do conceito de povo proposto pelos quatros vieses apresentado por Müller, conclui-se que, em uma análise conceitual e teórica o Estado Democrático de Direito Brasileiro abarca todos esses vieses: o povo como povo ativo, devido à representação do povo pela regra majoritária; o povo como instância global de atribuição de legitimidade, já que o povo é aquele que se sujeita ao ordenamento jurídico interno. No que se refere ao povo como ícone, esse visa a unificação do povo, atendendo também a minoria, esse seria uma povo hipotético, uma vez que numa sociedade plural, como a brasileira, é impossível falar em uma unificação e por fim o povo como destinatário das prestações civilizatórias do Estado, em que o Estado deve ter ações positivas para atender as necessidades do povo, já que uma das finalidades do Estado Moderno é atender às necessidades do povo.

\subsection{DE FATO QUEM É O POVO CONSAGRADDO NA CONSTITUIÇÃO DA REPÚBLICA FEDERATIVA DO BRASIL DE 1988}

Teoricamente não há dúvida quem é o povo citado na CR/88, mas e de fato esse povo existe? Para Müller (2010, p. 98) “na verdade o povo ainda está por ser criado”. E ainda acrescenta que:

Constituições democráticas e os titulares de funções do seu respectivo sistema de dominação preferem - e falam mais frequentemente - do "povo". A razão disso é simples: eles precisam justificar-se, como todas as formas de poder. E aqui a invocação do povo fornece a legitimação mais plausível. (MÜLLER, 2010, p. 93)

Sendo assim, pontuando de uma forma cruel, para não dizer realista, tem-se que no Estado Democrático de Direito os governantes em nome do povo e para o povo são capazes de cometerem diversas atrocidades para o proveito próprio e ilegítimo do poder que esse próprio povo os delegou.

No estado democrático brasileiro troca-se os interesses dos indivíduos em interesses de determinados grupos, consolidando a influência das classes dominantes em todas as esferas de poderes em detrimento dos indivíduos. De fato há a luta entre qual classe dominante irá atingir seus objetivos, momento em que cada uma delas busca dominar a maior quantidade de indivíduos possíveis. Para tanto usam de seu poder econômico quanto, e principalmente, do seu poder político, através de financiamento de eleições e outros interesses políticos.

Na concepção de Lênio Luiz Streck e José Luis Bolzan de Morais (2010) o que se tem no Brasil é a entrada em cena cada vez maior de grupos de interesses que patrocinam o jogo político em detrimento dos indivíduos. Desaparece o poder oligárquico, em que uma 
determinada elite controla a cena pública, mas, em contrapartida, há a multiplicação de elites que visam à dominação política e que concorrem entre si.

Nessa senda, a expressão constitucional “o poder emana do povo” restringe a um determinado povo e exclui grande parte de indivíduos brasileiros. Para Paulo Bonavides "No Brasil falta ao povo, atraiçoado de elites falsamente representativas, recobrar a razão libertária de seu destino"(2005, p.1-10). Ademais:

[...] a disposição constitucional de que todo poder emana povo e em seu nome é exercido, é inverídica na primeira parte, mas efetiva na segunda, pois nunca nos faltaram governantes atuando como simples representantes verbais desse ente soberano, inclusive para manter e justificar a ditadura das oligarquias. [...]; e se consideramos enfim o poder, estamos diante de uma indústria transformadora, que estabeleceu e aperfeiçoou soluções casuísticas de oportunismo sem grandeza para manipular o voto popular, converter derrotas de opinião em triunfos eleitorais, confiscar a autonomia do sufrágio e neutralizar o que ainda resta da minoria participante, onde se aloja o princípio democrático ou tem expressão aquela realidade que se chama povo. (BONAVIDES, 2012, p. 338,339)

As elites que visam a dominação política utilizam do poder do sistema capitalista para atingir os seus fins, através do capital manipulam, compram, subordinam e ameaçam a classe não dominante, e esta última se deixa seduzir pela dominante ou simplesmente aceita as condições impostas por não ter meios para lutar contra, já que o Estado que seria o responsável por protege-las se omite em detrimento da classe dominante.

Analisando o conceito de Müller sobre o povo e fazendo ponderações de relevância para complementar o acima dito Paulo Bonavides afirma:

\footnotetext{
Afigura-se-nos que, esse conceito, Muller o concebe por artigo de luta com que neutralizar o mau uso, o frequente abuso, em suma, a distorcida instrumentalizacao da imagem carismatica do povo-icone pelos poderes instituidos e privilegiados que govemam a sociedade.

[...]

A elite hegemonica desfruta o poder, sempre em proveito proprio, fazendo do povoicone a base moral do status quo e da legitimacao. E o que a historia, o passado, a tradicao de duzentos anos de continuísmo social da burguesia e das cartas constitucionais atraicoadas nos certificam. (BONAVIDEZ, 2001, p. 54)
}

Nesse contexto, nota-se claramente a abstenção do Estado no momento em que deveria intervir, uma vez que compete ao Estado o objetivo de construir uma sociedade livre, justa e solidária, bem como reduzir as desigualdades sociais, para tanto deve o Estado se investir a fim de proteger as classes dominadas, ou seja, incluir as classes minoritárias em seus programas de governo, objetivando diminuir as desigualdades e, claro, visando alcançar os seus fins de democracia. Müller (2005) afirma que um estado constitucional democrático deve regular e influenciar os mercados para que a sociedade possa continuar sendo razoavelmente justa. 
De fato, assim deveria ser, já que ao contrário a sociedade está ameaça pela exclusão social, em que as várias elites dominam e os grupos minoritários vão se formando ao ponto que a soma de todos os grupos minoritários se totalizam na maior parte da sociedade, quando se trata do aspecto quantitativo.

Há um descompasso entre a política de inclusão apresentada como uma consequência do Estado Democrático de Direito, uma vez que se pauta na finalidade de transformar a sociedade através da inclusão social, com o sistema capitalista que por si só caracteriza como uma economia de exclusão.

Um projeto estatal que se vê confrontado com a finalidade de transformar a
sociedade, sobretudo na perspectiva da inclusão social, como projeto político
constitucional, e, de outro lado, delimitado com as proteções, resguardados e
salvaguardas impostos por um economia capitalista que, não mais podendo excluir
totalmente, estabelece limites às possibilidades de concretização de um tal projeto,
naquilo que restou do capitalismo de produção, e descomprometido totalmente
naquilo que se apresenta agora como capitalismo financeiro. Ou seja, vive-se, já,
para além da dualidade: política de inclusão vs. economia de exclusão ou, no limite,
de semi-inclusão. (MORAIS, 2011, p. 64)

Diante desse duelo política de inclusão versus economia de exclusão tem-se uma multiplicidade de elites dominantes, preservadas pelo capitalismo financeiro, e por outro lado, encontra-se a diversidade de grupos minoritários, excluídos do capitalismo em voga. Consubstancia, portanto, uma sociedade altamente plural, em que o conceito de povo, perante o sistema democrático, deve abarcar a todos indistintamente, sob consequência de se consubstanciar em uma democracia fragilizada:

[...] Cumpre salientar que o ataque mais profundo nessa direção provém da exclusão social, a qual se amplia e agrava graças à globalização, como indicam as evidências empíricas. A exclusão se afirma inequivocamente às expensas do Estado Democrático de Direito e do Estado de Bem-Estar Social; ela deslegitima o governo, pois faz com que o povo ativo, o povo enquanto instância de atribuição e o povodestinatário degenerem em "povo" como ícone.

Num grau mais acentuado, a exclusão chega até a "desestatizar" o Estado constitucional exigente, que só pode ser justificado como Estado universal e não como um Estado ao qual se sobrepõe tiranicamente o metacódigo inclusão/exclusão. E no grau no qual os mercados globais ditam a política e tornam inoperantes as chances de monitoramento por parte dos governos, o conceito de democracia cai no vazio, como freqüentemente tem ocorrido. (MÜLLER, 2005, p. 01-10)

Ocorre que o conceito de povo que abarca indistintamente a todos como na eloquente expressão “o poder emana do povo”, é conceito na acepção de povo enquanto ícone, uma vez que no campo fático o que há, como explica Müller (2015) é a miséria maciça, primordialmente econômica, no que tange ao povo-destinatário; logo a miséria sócio-cultural, que acarreta a apatia política, referindo-se ao povo ativo; e, por fim, a exclusão jurídica em acepção mais estrita (violência ilegal, desigualdade inconstitucional, negação da proteção 
jurídica, impunidade dos responsáveis pela opressão) consistem violações do status do povo como instância de atribuição. Degenerando em povo como ícone.

Nessa senda, tem-se que quando se remete que a democracia é um governo do povo e para o povo, pelo menos no Brasil, o povo a que se destina o Estado Democrático de Direito é povo enquanto ícone, esvaziando o conceito e os objetivos da democracia. Consequentemente, enfraquecendo o campo dos direitos humanos: "fora da democracia não há espaço para os direitos humanos, sem a democracia não solução possível para os déficits humanitários" (MORAIS, 2011, p. 111), bem como esvaziando os direitos fundamentais quando se trata do âmbito jurídico interno, já que "entre os direitos fundamentais $e$ a democracia se verifica uma relação de interdependência e reciprocidade" (SARLET, 2010, p. 61).

Afim de não enfraquecer ou esvaziar o Estado Democrático de Direito é preciso que o Estado garanta no mínimo direitos fundamentais aos indivíduos e a coletividade, efetivando tanto as leis internas quanto as leis externas que abrangem os direitos fundamentais ou, na concepção internacional, os direitos humanos.

Ademais, a adesão e a efetividade das convenções ou dos tratados internacionais de direitos humanos colaboram de forma incisiva para a consolidação e preservação da democracia no Estado Brasileiro, conforme explica Antônio Augusto Cançado Trindade:

\footnotetext{
Assim, os valores democráticos têm incidência nos próprios métodos de interpretação dos tratados de direitos humanos. O "sentido autônomo" de que se revestem os termos dos tratados de direitos humanos, - respaldado pela jurisprudência das Cortes Europeia e Interamericana de Direitos Humanos, constitui outro importante elemento de interpretação no sentido de resguardar a letra e o espírito dos tratados de direitos humanos face a eventuais desvios dos ordenamentos jurídicos internos. Nessas circunstâncias, os tratados de direitos humanos vêm resguardar os direitos ameaçados, contribuindo assim à sua prevalência e à preservação e consolidação dos valores democráticos. (TRINDADE, 1999 , p. 243-244).
}

Observa-se, então, a fragilidade da democracia perante a diversidade daquilo que compõe o povo, pois o que se encontra é um povo como ícone, característica que esvazia a democracia em seu sentido completo, podendo falar em uma democracia fragilizada, já que o povo que a representa ou que a institui é um povo degenerado em povo enquanto ícone. E por conseguinte, haverá a não efetivação dos direitos humanos, já que para isso é necessário a consolidação da democracia. 


\section{CONCLUSÃO}

O Estado se transforma na medida em que a sociedade que o compõe se modifica, já que devido às essas modificações a sociedade proclama que o Estado se adeque atendendo as novas necessidades que vão surgindo com as classes que emergem.

Incialmente, como a formação dos Estados Modernos, tem-se o absolutismo que atende a necessidade dos reis, sendo que nesse período o Estado representava os interesses dos reis. Mas não satisfeito com essa forma estatal e na medida em que emerge uma nova classe, a burguesia, que luta por um Estado que atenda as suas necessidades, que são, precipuamente, a não intervenção dos Estados, surge o Estado Liberal. Logo mais, nasce outra classe, o proletariado, com interesses diversos, que necessitam de um Estado interventor para responder às necessidades de cunho social que proclamam, momento em que o Estado Liberal se transforma em Estado Social, a fim de realizar os anseios dessa classe.

Perante essa constante transformação da sociedade emerge o Estado Democrático de Direito que visa governar para o povo e em nome do mesmo. Tanto que a Constituição da República Federativa do Brasil de 1988 proclama que "todo poder emana do povo”. A problemática que surge, então, é definir que é esse povo.

Diante da análise feita durante o presente trabalho, pode-se concluir, que o Estado Democrático de Direito, como as demais formas estatais, sempre atendeu às necessidades de determinadas classes, iniciando-se pelos reis, depois a burguesia, logo o proletariado e por fim o povo. Ocorre que esse povo a quem a democracia tanto se refere, de fato não é o povo definido nos quatros viesses apontados e analisados por Müller, verdadeiramente é um povo específico, qual seja, o povo ícone.

O povo enquanto ícone é um povo que não é divididos pela diferença segundo o gênero, as classes sociais, a etnia, a língua, a cultura e a religião. Lugar em que não há dominação de uma classe sobre a outra, ou seja, um povo que, de fato, não existe.

Portanto, diante a realidade, percebe-se que não é esse o povo que o Estado Democrático de Direito atende. Troca-se os interesses dos indivíduos em interesses de determinados grupos, consolidando a influência das classes dominantes em todas as esferas de poderes em detrimento dos indivíduos. Tem-se exclusão de muitos diante da realidade, o que não deveria ser o resultado de uma democracia, já que essa visa à transformação da realidade, bem como a inclusão de todos. 
Nesse diapasão, é possível concluir que o que se tem na realidade é uma democracia fragilizada. Uma vez que ela representa as classes dominantes, ou melhor dizendo, representa uma variedade de elites, em que muitos são excluídos, não cumprindo seu objetivo de transformar a realidade, incluindo as minoras marginalizadas.

Dessa forma o que há é um esvaziamento da democracia em seu sentido completo, podendo falar em uma democracia fragilizada, já que o povo que a representa ou que a institui é um povo degenerado em povo enquanto ícone. E, por conseguinte, haverá a não efetivação de forma completa dos direitos humanos, já que para isso é necessário uma democracia consolidada. 


\section{BIBLIOGRAFIA:}

BOBBIO, Noberto. Teoria Geral da Política: A Filosofia Política e as Lições dos Clássicos. Rio de Janeiro: Elsevier, 2000.

BONAVIDES, Paulo. Do estado liberal ao estado social. 7. ed. São Paulo Malheiros, 2001.

BONAVIDES, Paulo. Teoria Geral do Estado. 9a ed. São Paulo: Malheiros. 2012.

BONAVIDES, Paulo. AS BASES DA DEMOCRACIA PARTICIPATIVA. Disponível em http://www.achegas.net/numero/vinteesete/p_bonavides_27.htm. Acessado em 15 de julho de 2016.

BONAVIDES, Paulo. TEORIA CONSTITUCIONAL DA DEMOCRACIA ARTICIPATIVA. Por um Direito Constitucional de luta e resistência. Por uma Nova Hermenêutica. Por uma repolitização da legitimidade. São Paulo: Malheiros Editores. 2001.

CANOTILHO, Joaquim José Gomes. Estado de Direito. 1999. Disponível em http://www.libertarianismo.org/livros/jigcoedd.pdf. Acessado em 13 de julho de 2016.

MORAIS, José Luiz Bolzan de. As crises do Estado e da Constituição e a Transformação Espaço-Temporal dos Direitos Humanos. $2^{\text {a }}$ Ed. Porto Alegre: Livraria do Advogado Editora. 2011.

MÜLLER, Friedrich. QUE É O POVO? A questão fundamental da democracia. $5^{\text {a }}$ Ed. São Paulo: Editora Revista dos Tribunais. 2010.

MÜLLER, Friedrich. Democracia e exclusão social em face da globalização. Rev. Jur., Brasília, v. 7, n. 72, p.01-10, maio, 2005. Disponível em https://revistajuridica.presidencia.gov.br/index.php/saj/article/view/444. Acessado em 07 de agosto de 2016.

PIOVESAN, Flávia. DEMOCRACIA, DIREITOS HUMANOS E GLOBALIZAÇÃO ECONÔMICA: DESAFIOS E PERSPECTIVAS PARA A CONSTRUÇÃO DA CIDADANIA NO BRASIL. http://www.dhnet.org.br/direitos/militantes/flaviapiovesan/piovesan_democracia_dh_global_e conomica_br.pdf. Acessado em 07 de agosto de 2016.

ROSANVALLON, Pierre. El buen gobierno. $1^{\circ}$ Ed. Ciudad Autónoma de Buenos Aires: Manantial, 2015.

SARLET, Ingo Wolfgang. A EFICÁCIA DOS DIREITOS FUNDAMENTAIS. UMA TEORIA GERAL DOS DIREITOS FUNDAMENTAIS NA PERSPECTIVA

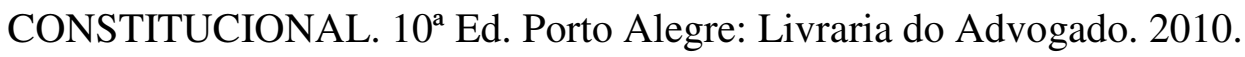

STRECK, Lenio Luiz; MORAIS, José Luis Bolzan de Morais. Ciência Política \& Teoria do Estado. $7^{\text {a }}$ Ed. Porto Alegre: Livraria do Advogado. 2010.

TRINDADE, Antônio Augusto Cançado. TRATADO DE DIREITO INTERNACIONAL DOS DIREITOS HUMANOS. V. II. $1^{\text {a }}$ Ed. Porto Alegre: Sergio Antonio Fabris Editor, 1999. 